\title{
International Cross-Sectional Study on the Effectiveness of Okada Purifying Therapy, a Biofield Therapy, for the Relief of Various Symptoms
}

\author{
Kiyoshi Suzuki, MD, PhD, ${ }^{1,2}$ Seiya Uchida, MSc, PhD, Tomoaki Kimura, MSc, PhD, \\ Hideaki Tanaka, $\mathrm{PhD}{ }^{1}$ and Hiroshi Katamura, $\mathrm{MD}, \mathrm{PhD}^{1,2}$
}

\section{Abstract}

Objective: To investigate whether differences exist in the effectiveness/safety of a single session of Okada Purifying Therapy (OPT), a type of biofield therapy, among those from different ethnicity/cultures, and to analyze factors associated with the outcomes in a real-world setting.

Design: Pre-post test design using convenience sampling methods.

Setting: Home setting.

Subjects: A total of 11,303 individuals aged 16 years or older from 14 different countries $(>1000$ individuals each from Japan, the United States, Thailand, Chile/Peru, and $<200$ individuals each from Portugal, Spain, Argentina, Mexico, Brazil, South Korea, Taiwan, Belgium, and France). More than $50 \%$ of the subjects were themselves OPT practitioners, and more than $50 \%$ of the treatments were administered in an environment where the practice of OPT was promoted.

Intervention: Participants received a single session of OPT lasting $30 \mathrm{~min}$ or longer from the volunteer practitioners. They self-reported the changes in overall symptoms, physical pain, anxiety/depression, and dizziness/palpitation.

Outcome measures: Improvement/exacerbation rates of each symptom and factors associated with symptom improvement were analyzed.

Results: Of the participants, $77.5 \%, 75.6 \%, 78.4 \%$, and $73.8 \%$ reported an improvement of overall symptoms, physical pain, anxiety/depression, and dizziness/palpitation, respectively. The improvement rates were consistently higher among participants from Chile/Peru than those from Japan, the United States, and Thailand $(p<0.001)$, and among those who had received a longer therapy $(p<0.001)$. Spanish/Portuguese speaking countries almost always showed high improvement rates; conversely, Japan showed a lower rate in each symptom. Participants' gender, reasons for participation, previous experience, and location of the session were also associated with the improvement of different symptoms. These findings occurred regardless of the participants' age or presence/absence of illness. In terms of safety, the exacerbation rates of symptoms were $2.8 \%, 2.5 \%, 0.8 \%$, and $1.7 \%$, respectively. Of those who expressed symptoms exacerbation, $71.6 \%$ recovered in a few hours. None of them needed emergency medical treatment.

Conclusions: In those who were often sympathetic to OPT and/or in an authorized location, OPT was effective and safe across countries with ethnic/cultural differences; however, participants' country of residence and duration of the session were independently associated with the changes in various symptoms. (ClinicalTrials.gov NCT03994809).

Keywords: biofield therapy, energy healing, international study, ethnicity, effectiveness, adverse events

\footnotetext{
${ }^{1}$ General Incorporated Foundation MOA Health Science Foundation, Tokyo, Japan.

${ }^{2}$ Tokyo Ryo-in MOA Takanawa Clinic, Tokyo, Japan.
}

(C) Kiyoshi Suzuki et al. 2020; Published by Mary Ann Liebert, Inc. This Open Access article is distributed under the terms of the Creative Commons License (http:/ / creativecommons.org/licenses/by/4.0), which permits unrestricted use, distribution, and reproduction in any medium, provided the original work is properly cited. 


\section{Introduction}

B IOFIELDS ARE EXPLAINED by Jain et al. as "endogenously generated fields, which may play a significant role in information transfer processes that contribute to an individual's state of mental, emotional, physical, and spiritual wellbeing." 1 They further describe biofield therapy as "noninvasive, practitioner-mediated therapies that explicitly work with the biofield of both the practitioner and recipient to stimulate a healing response in the recipient." Healing Touch, Reiki, Therapeutic Touch, and Johrei are examples of such practices. ${ }^{1}$

The scientific mechanism of biofield therapy (or energy healing) remains to be clarified ${ }^{1-5}$; meanwhile, the therapy has been reported to ameliorate pain in different illnesses, $1,6-12$ psychologic symptoms, and/or anxiety. ${ }^{3,8,10-14}$ Biofield therapy also reportedly influenced the autonomic activity in patients early after acute coronary syndrome ${ }^{15}$ and increased in positive emotional state and well-being. ${ }^{3,11,15,16}$ In the context described by Jain et al., ${ }^{1}$ Okada Purifying Therapy (OPT), ${ }^{17,18}$ initially formulated by Mokichi Okada (1882-1955) in the mid 1930s in Japan, is a type of biofield therapy.

\section{Okada Purifying Therapy}

OPT has been practiced generally in home settings to relieve various symptoms. The general principles underlying OPT are based on Okada's concepts. ${ }^{17,18}$ He stated that all physical materials and creatures are the mixture of the "body" in the present world and the "spirit" belonging to the spiritual world, which mutually interact. Synthetic substances or metabolic wastes in the body become toxins, which cause many forms of illnesses, and transform into defilement in the spirit. Furthermore, bad behavior or idea produces defilement in the spirit and become toxins in the body. Removal of toxins in the body, that is, elimination of defilement in the spirit, results in the fundamental solution of any type of illness and leads to true happiness.

During the training course, OPT practitioners study the concept of OPT, the reason of its effectiveness, and methods to remove toxins from the body. Stiff and/or warm spots on the body represent accumulated toxins, which are the key areas to administer OPT. With permission from the recipient, the practitioner places his/her palm on the recipient's head, neck, shoulder, upper back, and lower back in sequence to search for stiff and/or warm spots emanating from the body.

During the therapy, the practitioner absorbs a "life-force energy" permeating in the universe and raises his/her hand forward toward the recipient with the palm directed toward the recipient, with feelings of devotion toward symptom improvement and happiness for the recipient. The practitioner radiates the "life-force energy" from his/her palm toward the key areas on the recipient's body, envisioning the energy penetrating through the recipient's body. The practitioner uses his/her hands alternately during the administration of OPT. The distance between the palm and the body is usually 1-2 feet, with each session typically lasting 30 to $60 \mathrm{~min}$.

According to Okada, OPT invigorates the self-healing ability to remove accumulated toxins, thereby facilitating physical-mental-spiritual health for both recipients and practitioners. ${ }^{17,18}$ The practitioner explains the concept of OPT described above to the recipient before the treatment.
Beginning in 2000, MOA International Corporation (MOA) developed an accreditation system for OPT. ${ }^{17}$ Anyone can practice OPT as noncertified practitioners by taking a basic training course. To be certified as practitioners, individuals can take an advanced course and pass an examination approved by the corporation. More than 50,000 out of $\sim 800,000$ practitioners in Japan and more than 20,000 out of 200,000 practitioners outside Japan had been certified as of February 2020.

The research team previously reported that the power values of alpha waves detected by electroencephalograms increased $^{19,20}$ and the heart rate variability in electrocardiograms changed in OPT sessions, during which the recipients were unaware of whether or not they were receiving the therapy. ${ }^{19,21,22}$ In a separate cross-sectional study in Japan, $\sim 70 \%$ of the participants reported improved symptoms after a single OPT session, although the improvement rates varied according to gender, location and duration of the session, and reasons for using OPT. ${ }^{23,24}$ Long-term practice of OPT has been described to improve menopausal symptoms, ${ }^{25}$ anemia, and survival rate in patients with sickle cell disease, ${ }^{26}$ and widespread pain in those with fibromyalgia. ${ }^{27}$

To promote physical-mental-spiritual well-being, MOA recommends combination of health programs (Okada Health and Wellness Program), which consists of OPT along with diet and art components. ${ }^{17}$ The team reported that the regular practice of Okada Health and Wellness Program helped $\sim 80 \%$ of patients with hypertension to become normotensive, and $\sim 30 \%$ either reduced/stopped taking medication. ${ }^{28}$ Further, simultaneous practice of OPT, diet, and art components were more likely to improve quality of life (QOL) $)^{29}$ evaluated with the 10-item MOA quality of life questionnaire (MQL$10),{ }^{30}$ which is described further in the Methods section.

While biofield therapy often includes a holistic and spiritual meaning, ethnic differences were reportedly observed in the use of energy therapies ${ }^{31,32}$ and spiritual practices. $^{33,34}$ The outcomes of biofield therapy may be influenced by individual's ethnic/cultural background as well as their expectation, situations of receiving the therapy, and relationship with the practitioner. ${ }^{35-38}$ The degree of acculturation and/or duration of residence in a certain country may also play a role. ${ }^{39}$ Ghiasuddin et al. reported that pediatric oncology patients who received healing touch and their parents in Hawaii had attitudes/beliefs around health care that were rooted in their traditional cultural values with the younger generation being less traditional. ${ }^{40}$ To the extent of the research team's knowledge, it has not been reported whether the recipient's ethnic/cultural background influences the outcomes of biofield therapy. Therefore, the present study aimed (1) to investigate whether the effectiveness/safety of a single session of OPT in various settings differ across different ethnicities/cultures, and (2) to analyze factors associated with the outcomes in a real-world setting. This study was conducted in accordance with the Declaration of Helsinki 1975, as revised in 2013, and was approved by the Institutional Review Board and the Research Ethics Committee of the MOA Health Science Foundation.

\section{Methods}

This study aimed to include as many participants as possible in a real-world setting, which would have been 
impaired by introducing artificially created control groups. Therefore, the research team chose a design to recruit the participants using convenience sampling methods without assigning control groups.

\section{Investigators}

The first author delivered a lecture to OPT instructors, $\sim 100$ in Japan and 25 outside Japan, to explain the purpose of the study and to provide guidance for administering the questionnaires. This initial lecture was video recorded, which the instructors used to train other certified OPT practitioners as investigators. The training was conducted several times each in 222 locations in Japan and 30 times in 15 locations outside Japan. Explanation was provided on how to recruit participants, to administer OPT, and to use record sheets.

The investigators were not financially reimbursed for conducting the OPT sessions or for participating in this study. Noncertified practitioners took part in this study as recipients, but not as investigators. The OPT sessions were carried out according to the protocols provided by MOA, the outline of which is described in the introduction.

\section{Participants}

The research team developed a Japanese version of the information sheet and the questionnaires. They were translated into English, Spanish, French, Portuguese, Thai, Chinese, and Korean languages under the responsibility of each regional headquarter of MOA. The investigators used the information sheet and word-of-mouth to recruit participants in 14 different countries. From January 2008 to September 2010, subjects received a single session of OPT from the investigators at the MOA's affiliated institutes or workshops, the investigator's house, or the participant's home.

Inclusion criteria were as follows: (1) individuals who agreed to receive a single session of OPT for $30 \mathrm{~min}$ or longer from the investigators, (2) were able to self-evaluate the changes in their symptoms, (3) competent to answer the questionnaires, and (4) aged 16 or older. All individuals agreed to participate without receiving an honorarium. Certified practitioners could participate as both investigators and participants, provided that they met the inclusion criteria. There were no specific exclusion criteria for this study.

\section{Questionnaires}

Participants completed a demographic questionnaire before the OPT session. They self-evaluated the severity of the following categorized symptoms by means of a 5-point Likert-type scale ranging from 0 (none) to 4 (extreme) before and after an OPT session: physical pain, anxiety/depression (psychologic symptoms), and dizziness/palpitation (autonomic symptoms). They also self-reported the changes in overall symptoms (improved, no change, or exacerbated) after the session (Fig. 1). Those who expressed symptom exacerbation were asked to report afterward what they had done to relieve their symptoms and when they recovered from the exacerbation.

To evaluate participants' QOL, a free QOL assessment questionnaire applicable to a large sample size was required. Therefore, the MQL-10 questionnaire ${ }^{30}$ was chosen for use, which was previously developed for this study. The MQL-
10 score ranges from 0 to 40 , with higher scores indicating better QOL, and its minimal important difference is three points. The Cronbach's alpha coefficient of the MQL-10 was 0.872 at baseline and 0.879 at follow-up, both above cutoff point of 0.8 , suggesting a good internal consistency. The correlation coefficient with WHOQOL-26 and SF-36 (mental health domain) was 0.81 and 0.64 , respectively. ${ }^{30}$ Participants completed the MQL-10 questionnaire before the OPT session.

\section{Analyses}

The research team classified changes in symptoms for each category into "improved," "no change," or "exacerbated" by comparing the symptom levels before and after the OPT session. The team used the data from the participants who had symptom levels of 1,2 , or 3 at baseline (Fig. 1). This criterion was used because a "no change" response from participants who had no symptoms (level 0) at baseline would have a different meaning than a "no change" response would have for participants whose symptoms had existed before the OPT session. Similarly, participants with extreme symptoms (level 4) at baseline could not report that the treatment exacerbated their symptoms because level 4 was the highest level available, with the result that participants' reports of "no change", would not reflect an exacerbation of symptoms.

The authors used the Japanese SPSS version 25 (IBM SPSS Statistics, Tokyo, Japan) for data analyses. To account for potential risk of misclassification of participants from Chile being sorted into those from Peru, in the regional headquarter of both countries, data from Chile and Peru were classified into Chile/Peru group. Due to the limited number of participants from Belgium and France, data from each country were classified into Belgium/France group. More than 1000 individuals each from Japan, the United States, Thailand, and Chile/Peru, and 26-136 subjects each from the other nine countries participated and met the inclusion criteria of this study (Table 1).

Because of large discrepancies in the number of participants between countries, the following statistical analyses were conducted between the participants from Japan, the United States, Thailand, and Chile/Peru. A Kruskal-Wallis test was used to compare ordinal variables between four countries. If results indicated statistical significance $(p<0.05)$, the Mann-Whitney test was further conducted to compare two countries, in which a $p$-value of 0.0083 was designated as the cutoff point for statistical significance according to the Bonferroni correction.

Then the authors conducted the logistic regression analyses of the factors associated with the changes in symptoms (Fig. 1). The category of "no change or exacerbation in symptoms" was used as the reference. Before conducting analysis, the team created three subgroups for each variable to divide the total data-units into comparable sets. The age groups (16-49, 50-69, and $\geq 70$ years), duration groups (30, $31-50$, and $\geq 51 \mathrm{~min}$ ), and MQL-10 groups ( $\leq 25,26-30$, and $\geq 31$ ) included an approximately equal number of individuals in each subgroup. A $p$-value of less than 0.05 was considered statistically significant.

To compare the results of the research team's previous study from 2007, which was conducted within Japan, ${ }^{24}$ 


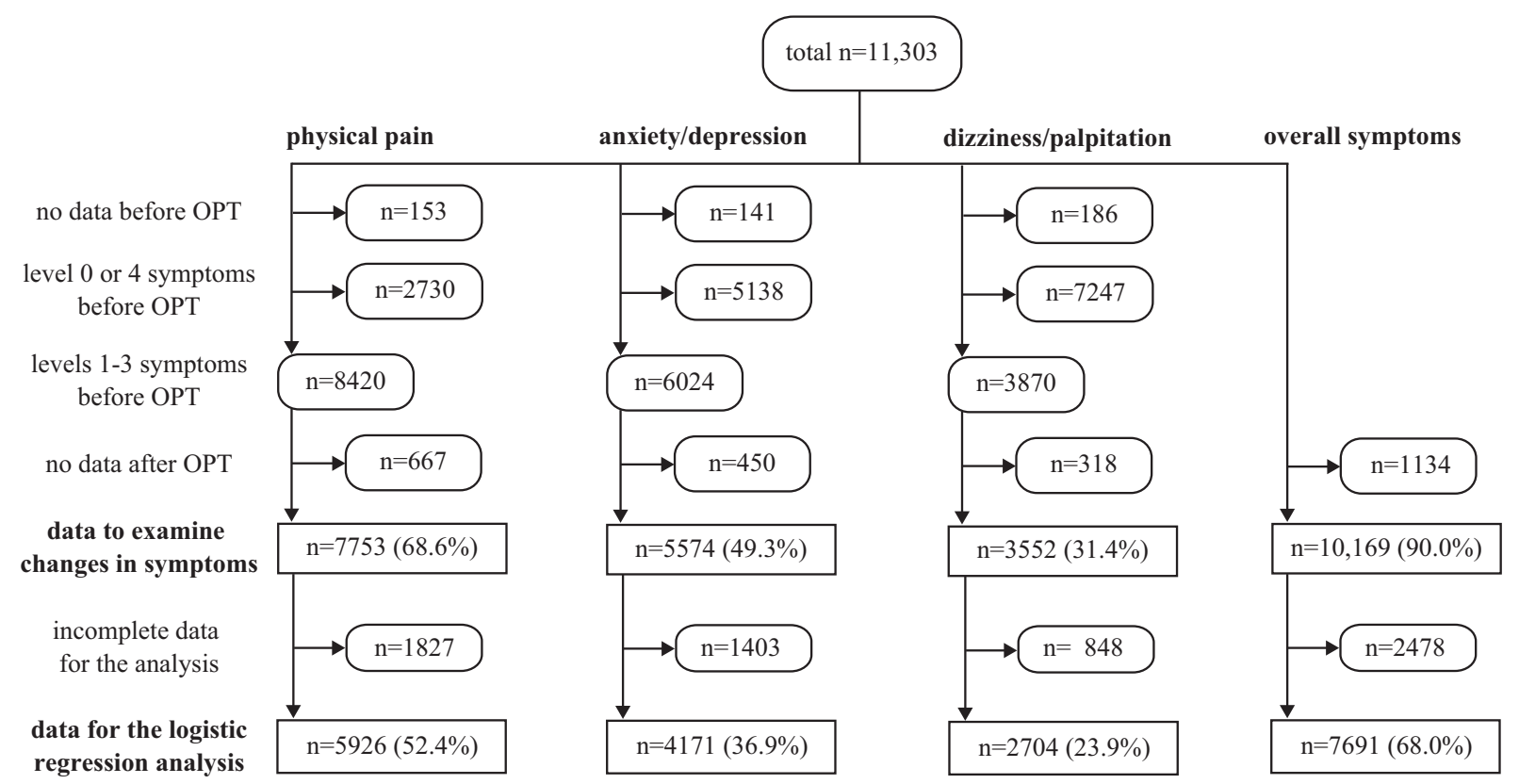

FIG. 1. Number of analyzed data of each symptom. Individuals who met the inclusion criteria are shown as numbers and proportions (\%) of the total participants. no data, the level of symptoms was not reported; incomplete data, one or more characteristics were not reported. OPT, Okada Purifying Therapy.

Table 1. Basic Characteristics of the Participants (TOTAL $N=11,303)$

\begin{tabular}{lc}
\hline Country of residence $(n=11,303)$ & $7187(63.6 \%)$ \\
Japan & $1276(11.3 \%)$ \\
The United States & $1176(10.4 \%)$ \\
Thailand & $1068(9.5 \%)$ \\
Chile/Peru & $136(1.2 \%)$ \\
Portugal & $116(1.0 \%)$ \\
Spain & $106(0.9 \%)$ \\
Argentina & $83(0.7 \%)$ \\
Mexico & $56(0.5 \%)$ \\
Brazil & $44(0.4 \%)$ \\
South Korea & $29(0.3 \%)$ \\
Taiwan & $26(0.2 \%)$ \\
Belgium/France & \\
Age $(n=11,191)$ & $3304(29.5 \%)$ \\
16-49 & $4557(40.7 \%)$ \\
50-69 & $3330(29.8 \%)$ \\
$\geq 70$ & \\
Gender $(n=11,041)$ & $2492(22.6 \%)$ \\
Male & $8549(77.4 \%)$ \\
Female & \\
Presence of illness $(n=10,498)$ & $5237(49.9 \%)$ \\
Absent & $5261(50.1 \%)$ \\
Present & \\
Reasons for participation $(n=10,575)$ & $3769(35.6 \%)$ \\
Health promotion & $2327(22.0 \%)$ \\
Symptom relief & $4479(42.4 \%)$ \\
Suggestion of others & \\
MQL-10 score $(10,626)$ & $3489(32.8 \%)$ \\
Low ( $\leq 25)$ & $4007(37.7 \%)$ \\
Moderate $(26-30)$ & $3130(29.5 \%)$ \\
High $(\geq 31)$ & \\
\hline
\end{tabular}

Categorical values are shown as numbers and proportions (\%). MQL-10, 10-item MOA quality-of-life questionnaire.
Japan's data in the present study were independently analyzed to determine the factors associated with the changes in physical pain, anxiety/depression, and dizziness/palpitation.

To estimate the influence of qualification as an OPT practitioner on the changes in symptoms, the improvement rates in various symptoms were compared between those with never/seldom OPT experience and those with qualification of OPT practitioner in participants from Japan, the United States, Thailand, and Chile/Peru, respectively. The Mann-Whitney test was used for the analyses, and a $p$-value of less than 0.05 was considered statistically significant.

\section{Results}

A total of 11,303 individuals from 14 different countries met the inclusion criteria for the analyses. Among participants who reported each question items appropriately, 7187/ 11,303 (63.6\%) were from Japan, 7887/11,191 (70.5\%) were aged 50 years or older, 8549/11,041 (77.4\%) were female, $5261 / 10,498(50.1 \%)$ reported presenting illness, and 4479/ $10,575(42.4 \%)$ participated through suggestion of others (Table 1). In terms of characteristics associated with OPT, $5607 / 11,114(50.4 \%)$ were qualified OPT practitioners, $4849 / 11,023(44.0 \%)$ experienced OPT for the first time or for the first time in a long time, 5480/10,846 (50.5\%) received the OPT session at an MOA affiliated institute or workshop, and 4737/11,303 (41.9\%) underwent intervention which lasted for $30 \mathrm{~min}$ (Table 2).

In each country, female participants accounted for more than $65 \%$; however, the percentage of those aged 50 years or older ranged from $34.5 \%$ (Taiwan) to $81.8 \%$ (South Korea). The minimum/maximum percentages of qualified OPT practitioner were 6.8\% (Portugal) and 65.9\% (South Korea), and the percentages of those who received OPT for the first time or for the first time in a long time ranged from $9.1 \%$ 
Table 2. Participants' Characteristics Associated With OKada Purifying Therapy (Total $N=11,303$ )

\begin{tabular}{ll}
\hline OPT practitioner $(n=11,114)$ & $5507(49.6 \%)$ \\
No & $5607(50.4 \%)$ \\
Yes & \\
Previous OPT experience $(n=11,023)$ & $4849(44.0 \%)$ \\
$\quad$ Never/seldom & $6174(56.0 \%)$ \\
Sometimes/regularly & \\
Location of OPT administration $(n=10,846)$ & $3071(28.3 \%)$ \\
Participant's home & $5480(50.5 \%)$ \\
MOA's institute/workshop & $2295(21.2 \%)$ \\
Investigator's house & \\
Duration of OPT administration $(n=11,303)$ & \\
30 min & $4737(41.9 \%)$ \\
$31-50$ min & $3244(28.7 \%)$ \\
$\geq 51$ min & $3322(29.4 \%)$ \\
\end{tabular}

Categorical values are shown as numbers and proportions (\%). MOA, MOA International Corporation; OPT, Okada Purifying Therapy.

(South Korea) to $82.2 \%$ (Thailand). Those who underwent the session at an MOA affiliated institute or workshop accounted for more than $70 \%$ in each country, except for Japan (27.0\%, Table 3).

A total of 3110 investigators who were identified by the registration number on the record sheets administered a single session of OPT to 9954 participants $(88.1 \%)$, whereas the investigator's registration number remained blank in the remaining 1349 record sheets $(11.9 \%)$. Of the 3110 investigators, $2125(68.3 \%)$ administered OPT to 1-2 participants, $661(21.3 \%)$ administered it to 3-5 subjects, 199 $(6.4 \%)$ to 6-9 subjects, and the remaining $125(4.0 \%)$ contributed more, ranging between 10 and 130 subjects.

\section{Self-reported changes in overall symptoms}

Of the total 10,169 participants who met the inclusion criteria for analyses, $7885(77.5 \%)$ self-reported an improvement of symptoms, 1999 (19.7\%) described no change, and the remaining $285(2.8 \%)$ experienced exacerbation of symptoms. Participants from Chile/Peru reported symptom improvement more often than those from Japan, the United
States, and Thailand ( $p<0.0083)$. Those from Japan included the lowest proportion of individuals who claimed symptom improvement $(p<0.0083)$. Spanish speaking countries and Portugal showed high improvement rates (Fig. 2).

The logistic regression analysis indicated that the following factors were independently associated with the symptom improvement: participants' country of residence, gender, reasons for participation, MQL-10 score, qualification as an OPT practitioner, previous OPT experience, location, and duration of the OPT administration (Table 4).

\section{Self-reported changes in physical pain}

Of the total 7753 participants who met the inclusion criteria for analyses, 5865 (75.6\%) stated an improvement in their symptoms, the level remained unchanged for 1696 (21.9\%), and 192 (2.5\%) expressed symptom exacerbation. Participants from Chile/Peru reported symptom improvement more often than those from Japan, the United States, and Thailand $(p<0.0083)$. Spanish speaking countries and Portugal also showed high improvement rates (Fig. 3).

The logistic regression analysis indicated that the following factors were independently associated with the symptom improvement: participants' country of residence, gender, previous OPT experience, and duration of the OPT administration (Table 5).

\section{Self-reported changes in anxiety/depression}

Of the total 5574 participants who met the inclusion criteria for analyses, $4368(78.4 \%)$ reported an improvement in symptoms, $1159(20.8 \%)$ described no change, and the remaining $47(0.8 \%)$ experienced exacerbation of symptoms. Chile/Peru had the highest proportion of individuals who expressed symptom improvement among the four countries $(p<0.0083)$. Those from Thailand reported symptom improvement more often than those from Japan and the United States $(p<0.0083)$. Spanish speaking countries and Portugal also showed high improvement rates (Fig. 4).

The logistic regression analysis indicated that the participants' country of residence, location, and duration of the OPT administration were independently associated with the symptom improvement (Table 6).

Table 3. Representative Patients' Characteristics in Each Country

\begin{tabular}{|c|c|c|c|c|c|}
\hline & Female gender & Aged $\geq 50$ years & OPT practitioner & $\begin{array}{l}\text { Never/seldom } \\
\text { OPT experience }\end{array}$ & $\begin{array}{l}\text { Therapy at an MOA } \\
\text { institute or workshop }\end{array}$ \\
\hline Japan & $5506 / 7083(77.7 \%)$ & $5468 / 7158(76.4 \%)$ & $4587 / 7131(64.3 \%)$ & $2170 / 7045(30.8 \%)$ & $1869 / 6910(27.0 \%)$ \\
\hline $\begin{array}{l}\text { The United } \\
\text { States }\end{array}$ & 888/1194 (74.4\%) & $880 / 1253(70.2 \%)$ & $496 / 1226(40.5 \%)$ & $699 / 1244(56.2 \%)$ & $1108 / 1207(91.8 \%)$ \\
\hline Thailand & 905/1164 (77.7\%) & $587 / 1173(50.0 \%)$ & 215/1171 (18.4\%) & $963 / 1171(82.2 \%)$ & $1057 / 1123(94.1 \%)$ \\
\hline Chile/Peru & $816 / 1030(79.2 \%)$ & $624 / 1032(60.5 \%)$ & $120 / 1018(11.8 \%)$ & 711/994 (71.5\%) & $967 / 1024(94.4 \%)$ \\
\hline Portugal & $94 / 132(71.2 \%)$ & $77 / 134(57.5 \%)$ & $9 / 132(6.8 \%)$ & $105 / 130(80.8 \%)$ & $87 / 131(66.4 \%)$ \\
\hline Spain & $83 / 105(79.0 \%)$ & $54 / 110(49.1 \%)$ & $18 / 106(17.0 \%)$ & $88 / 109(80.7 \%)$ & $109 / 113(96.5 \%)$ \\
\hline Argentina & $85 / 104(81.7 \%)$ & $57 / 102(55.9 \%)$ & $50 / 104(48.1 \%)$ & $37 / 104(35.6 \%)$ & $75 / 105(71.4 \%)$ \\
\hline Mexico & $61 / 79(77.2 \%)$ & $44 / 79(55.7 \%)$ & $30 / 77(39.0 \%)$ & $31 / 76(40.8 \%)$ & $80 / 81(98.8 \%)$ \\
\hline Brazil & $42 / 52(80.8 \%)$ & $40 / 52(57.7 \%)$ & $25 / 51(49.0 \%)$ & $23 / 53(43.4 \%)$ & $48 / 56(85.7 \%)$ \\
\hline South Korea & $29 / 44(65.9 \%)$ & $36 / 44(81.8 \%)$ & $29 / 44(65.9 \%)$ & $4 / 44(9.1 \%)$ & $40 / 44(90.9 \%)$ \\
\hline Taiwan & $19 / 29(65.5 \%)$ & $10 / 29(34.5 \%)$ & $16 / 29(55.2 \%)$ & $11 / 28(39.3 \%)$ & $23 / 28(82.1 \%)$ \\
\hline Belgium/France & $21 / 25(84.0 \%)$ & $20 / 25(80.0 \%)$ & $12 / 25(48.0 \%)$ & $7 / 25(28.0 \%)$ & $17 / 24(70.8 \%)$ \\
\hline
\end{tabular}

$\mathrm{a} / \mathrm{b}(\mathrm{c} \%)$ is expressed as the minimum or the maximum percentage in each characteristic. OPT, Okada Purifying Therapy. 


\begin{tabular}{|c|c|c|c|}
\hline & improved & no change & erbated \\
\hline Japan $(n=6262)$ & $72.7 \%$ & $24.1 \%$ & $3.2 \%-$ \\
\hline United States $(\mathrm{n}=1237)$ & $82.3 \%$ & $15.8 \%$ & $1.9 \%$ \\
\hline Thailand $(\mathrm{n}=1168)$ & $80.4 \%$ & $17.9 \%$ & $1.7 \%-$ \\
\hline Chile/Peru $(\mathrm{n}=940)$ & $94.9 \%$ & $3.6 \%$ & $1.5 \% *$ \\
\hline Portugal $(n=131)$ & $93.9 \%$ & $6.1 \%$ & $0.0 \%$ \\
\hline Spain $(n=111)$ & $86.5 \%$ & $9.9 \%$ & $3.6 \%$ \\
\hline Argentina $(n=103)$ & $88.3 \%$ & $6.8 \%$ & $4.9 \%$ \\
\hline Mexico $(n=80)$ & $92.5 \%$ & $2.5 \%$ & $5.0 \%$ \\
\hline Brazil $(n=49)$ & $69.4 \%$ & $22.4 \%$ & $8.2 \%$ \\
\hline South Korea $(n=37)$ & $78.4 \%$ & $13.5 \%$ & $8.1 \%$ \\
\hline Taiwan $(\mathrm{n}=26)$ & $73.1 \%$ & $19.2 \%$ & $7.7 \%$ \\
\hline Belgium/France $(n=25)$ & $72.0 \%$ & $12.0 \% \quad 16.0 \%$ & \\
\hline
\end{tabular}

FIG. 2. Self-reported changes in overall symptoms after a single session of Okada Purifying Therapy. ${ }^{*} p<0.0083$ by the Mann-Whitney test between the participants from Japan, the United States, Thailand, and Chile/Peru.

Table 4. Logistic Regression Analysis of the Factors Associated with an Improvement of Overall SyMPTOMS $(N=7691)$

\begin{tabular}{|c|c|c|c|}
\hline & Imp. $R$ & $\mathrm{p}$-Value & Odds ratio $(95 \% \mathrm{CI})$ \\
\hline \multicolumn{4}{|l|}{ Country of residence } \\
\hline Japan & $72.3 \%$ & & 1 \\
\hline The United States & $81.5 \%$ & $<0.001$ & $2.01(1.60-2.54)$ \\
\hline Thailand & $79.9 \%$ & $<0.001$ & $2.32(1.87-2.90)$ \\
\hline Chile/Peru & $95.0 \%$ & $<0.001$ & $8.31(5.33-13.0)$ \\
\hline Age & & 0.051 & \\
\hline \multicolumn{4}{|l|}{ Gender } \\
\hline Male & $66.6 \%$ & & 1 \\
\hline Female & $78.3 \%$ & $<0.001$ & $1.66(1.47-1.88)$ \\
\hline Presence of illness & & 0.25 & \\
\hline \multicolumn{4}{|l|}{ Reasons for participation } \\
\hline Health promotion & $82.4 \%$ & & 1 \\
\hline Symptom relief & $83.9 \%$ & 0.039 & $1.21(1.01-1.44)$ \\
\hline Suggestion of others & $66.5 \%$ & $<0.001$ & $0.64(0.54-0.75)$ \\
\hline \multicolumn{4}{|l|}{ MQL-10 score } \\
\hline Low $(\leq 25)$ & $76.0 \%$ & & 1 \\
\hline Moderate (26-30) & $77.2 \%$ & 0.50 & \\
\hline High $(\geq 31)$ & $72.9 \%$ & 0.049 & $0.87(0.75-0.99)$ \\
\hline \multicolumn{4}{|l|}{ OPT practitioner } \\
\hline No & $70.0 \%$ & & 1 \\
\hline Yes & $80.7 \%$ & $<0.001$ & $1.37(1.17-1.61)$ \\
\hline \multicolumn{4}{|l|}{ Previous OPT experience } \\
\hline Never/seldom & $69.4 \%$ & & 1 \\
\hline Sometimes/regularly & $80.3 \%$ & 0.001 & $1.32(1.12-1.55)$ \\
\hline \multicolumn{4}{|l|}{ Location of OPT administration } \\
\hline Participant's home & $67.9 \%$ & & 1 \\
\hline MOA's institute/workshop & $82.5 \%$ & $<0.001$ & $1.57(1.33-1.84)$ \\
\hline Investigator's house & $72.6 \%$ & 0.033 & $1.17(1.01-1.35)$ \\
\hline \multicolumn{4}{|l|}{ Duration of OPT administration } \\
\hline $30 \mathrm{~min}$ & $72.1 \%$ & & 1 \\
\hline $31-50 \mathrm{~min}$ & $72.9 \%$ & 0.002 & $1.23(1.08-1.41)$ \\
\hline$\geq 51 \mathrm{~min}$ & $83.2 \%$ & $<0.001$ & $1.78(1.53-2.07)$ \\
\hline
\end{tabular}

Categorical values are shown as proportions (\%). Reference category: no change or exacerbation in symptoms.

CI, confidence interval; Imp. R, improvement rate of symptoms in each factor; MQL-10, 10-item MOA quality-of-life questionnaire; OPT, Okada Purifying Therapy. 


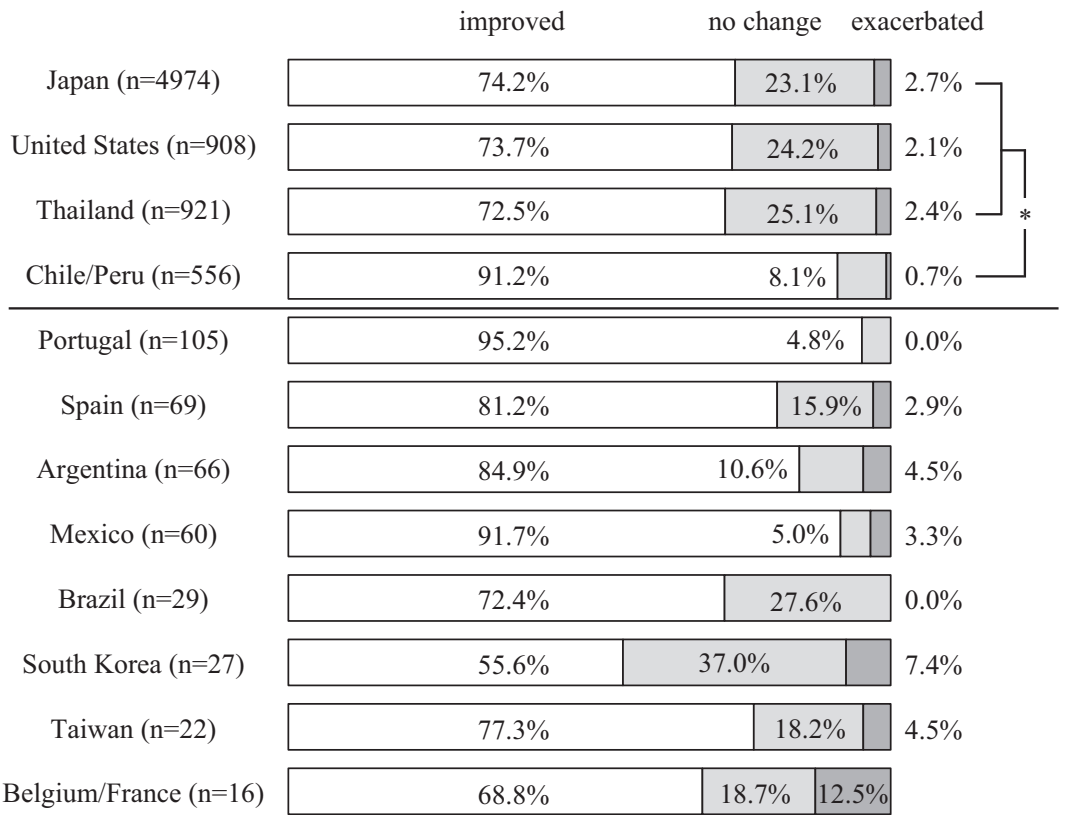

\section{Self-reported changes in dizziness/palpitation}

Of the total 3552 participants who met the inclusion criteria for the analyses, $2622(73.8 \%)$ described an improvement of symptoms, $869(24.5 \%)$ reported no change,

Table 5. Logistic Regression Analysis of THE FACTORS AsSOCIATED WITH AN IMPROVEMENT of Physical Pain $(N=5926)$

\begin{tabular}{|c|c|c|c|}
\hline & Imp. $R$ & $\mathrm{p}$-Value & $\begin{array}{l}\text { Odds ratio } \\
(95 \% \text { CI })\end{array}$ \\
\hline \multicolumn{4}{|l|}{ Country of residence } \\
\hline Japan & $73.8 \%$ & & 1 \\
\hline The United States & $73.9 \%$ & 0.11 & \\
\hline Thailand & $72.0 \%$ & 0.016 & $1.31(1.05-1.64)$ \\
\hline Chile/Peru & $89.4 \%$ & $<0.001$ & $3.78(2.50-5.71)$ \\
\hline Age & & 0.15 & \\
\hline \multicolumn{4}{|l|}{ Gender } \\
\hline Male & $71.5 \%$ & & 1 \\
\hline Female & $75.1 \%$ & 0.028 & $1.18(1.02-1.36)$ \\
\hline Presence of illness & & 0.40 & \\
\hline $\begin{array}{l}\text { Reasons for } \\
\text { participation }\end{array}$ & & 0.051 & \\
\hline MQL-10 score & & 0.10 & \\
\hline OPT practitioner & & 0.58 & \\
\hline \multicolumn{4}{|c|}{ Previous OPT experience } \\
\hline Never/seldom & $71.1 \%$ & & 1 \\
\hline Sometimes/regularly & $76.5 \%$ & 0.021 & $1.24(1.03-1.49)$ \\
\hline $\begin{array}{l}\text { Location of OPT } \\
\text { administration }\end{array}$ & & 0.76 & \\
\hline \multicolumn{4}{|c|}{ Duration of OPT administration } \\
\hline $30 \mathrm{~min}$ & $70.8 \%$ & & 1 \\
\hline $31-50 \mathrm{~min}$ & $74.1 \%$ & 0.011 & $1.21(1.05-1.41)$ \\
\hline$\geq 51 \mathrm{~min}$ & $78.8 \%$ & $<0.001$ & $1.51(1.29-1.77)$ \\
\hline
\end{tabular}

Categorical values are shown as proportions (\%). Reference category: no change or exacerbation in symptoms.

$\mathrm{CI}$, confidence interval; Imp. R, improvement rate of symptoms in each factor; MQL-10, 10-item MOA quality-of-life questionnaire; OPT, Okada Purifying Therapy. and the remaining $61(1.7 \%)$ expressed exacerbation of symptoms. Participants from Chile/Peru reported symptom improvement more often than those from Japan, the United States, and Thailand $(p<0.0083)$. Spanish/Portuguese speaking countries also showed high improvement rates (Fig. 5).

The logistic regression analysis indicated that participants' country of residence, location, and duration of the OPT administration were independently associated with symptom improvement (Table 7).

\section{Adverse events of OPT}

Among the 228 participants who reported exacerbation of symptoms after the intervention and what they had done to relieve their symptoms, $178(78.1 \%)$ waited it out, 46 $(20.1 \%)$ received further OPT session, $2(0.9 \%)$ took medications, and the remaining $2(0.9 \%)$ consulted a doctor. Of the 169 individuals who described the duration of symptom exacerbation, $121(71.6 \%)$ recovered in a few hours, and 19 $(11.2 \%)$ recovered in $24 \mathrm{~h}$. The exacerbation persisted for more than $24 \mathrm{~h}$ in the remaining $29(17.2 \%)$. None of them needed emergency medical treatment.

\section{Results of participants from Japan}

Of the participants from Japan who met the inclusion criteria for analyses, duration of the OPT administration was the consistent factor associated with the changes in physical pain, anxiety/depression, and dizziness/palpitation. Location of the session was also the independent factor associated with changes in anxiety/depression and dizziness/palpitation. Previous OPT experience was associated with changes in physical pain. Participants' gender was related to the changes in anxiety/depression (Table 8).

\section{Influence of qualification as an OPT practitioner on symptom improvement}

After receiving a single session of OPT at an MOA-affiliated institute or workshop, the improvement rates of overall 


\begin{tabular}{|c|c|c|c|}
\hline & improved & no change & erbated \\
\hline Japan $(n=3441)$ & $75.2 \%$ & $24.0 \%$ & $0.8 \% \square$ \\
\hline United States $(\mathrm{n}=588)$ & $74.5 \%$ & $24.8 \%$ & $0.7 \%$ \\
\hline Thailand $(\mathrm{n}=601)$ & $81.9 \%$ & $16.1 \%$ & $2.0 \%$ \\
\hline Chile/Peru $(n=605)$ & $92.4 \%$ & $6.8 \%$ & $0.8 \% *$ \\
\hline Portugal $(\mathrm{n}=90)$ & $90.0 \%$ & $10.0 \%$ & $0.0 \%$ \\
\hline Spain $(n=74)$ & $91.9 \%$ & $8.1 \%$ & $0.0 \%$ \\
\hline Argentina $(n=62)$ & $83.9 \%$ & $16.1 \%$ & $0.0 \%$ \\
\hline Mexico $(n=44)$ & $93.2 \%$ & $6.8 \%$ & $0.0 \%$ \\
\hline Brazil $(n=20)$ & $75.0 \%$ & $25.0 \%$ & $0.0 \%$ \\
\hline South Korea $(n=24)$ & $66.7 \%$ & $33.3 \%$ & $0.0 \%$ \\
\hline Taiwan $(n=11)$ & $63.6 \%$ & $36.4 \%$ & $0.0 \%$ \\
\hline Belgium/France $(n=14)$ & $71.4 \%$ & $28.6 \%$ & $0.0 \%$ \\
\hline
\end{tabular}

FIG. 4. Self-reported changes in anxiety/depression after a single session of Okada Purifying Therapy. $* p<0.0083$ by the Mann-Whitney test between the participants from Japan, the United States, Thailand, and Chile/Peru.

symptoms differed between those with never/seldom OPT experience and qualified OPT practitioners in the individuals from Japan $(66.2 \% / 83.5 \%)$, the United States $(75.7 \% / 90.9 \%)$, and Thailand $(76.8 \% / 96.4 \%)$, respectively $(p<0.05)$, but not in those from Chile/Peru (94.1\%/98.8\%). As for other symp-

Table 6. Logistic Regression AnAlysis OF THE FACTORS ASSOCIATED WITH AN IMPROVEMENT OF ANXIETY/DEPRESSION $(N=4171)$

\begin{tabular}{|c|c|c|c|}
\hline & Imp. $R$ & $\mathrm{p}$-Value & $\begin{array}{c}\text { Odds ratio } \\
(95 \% \text { CI })\end{array}$ \\
\hline \multicolumn{4}{|l|}{ Country of residence } \\
\hline Japan & $75.4 \%$ & & 1 \\
\hline The United States & $75.3 \%$ & 0.59 & \\
\hline Thailand & $81.9 \%$ & $<0.001$ & $1.73(1.28-2.33)$ \\
\hline Chile/Peru & $91.2 \%$ & $<0.001$ & $3.73(2.40-5.79)$ \\
\hline Age & & 0.40 & \\
\hline Gender & & 0.066 & \\
\hline Presence of illness & & 0.77 & \\
\hline $\begin{array}{l}\text { Reasons for } \\
\text { participation }\end{array}$ & & 0.080 & \\
\hline MQL-10 score & & 0.59 & \\
\hline OPT practitioner & & 0.71 & \\
\hline $\begin{array}{l}\text { Previous OPT } \\
\text { experience }\end{array}$ & & 0.55 & \\
\hline \multicolumn{4}{|l|}{ Location of OPT } \\
\hline Participant's home & $72.2 \%$ & & 1 \\
\hline $\begin{array}{l}\text { MOA's institute/ } \\
\text { workshop }\end{array}$ & $80.3 \%$ & 0.098 & \\
\hline Investigator's house & $78.7 \%$ & 0.007 & $1.32(1.08-1.61)$ \\
\hline \multicolumn{4}{|c|}{ Duration of OPT administration } \\
\hline $30 \mathrm{~min}$ & $75.7 \%$ & & 1 \\
\hline $31-50 \mathrm{~min}$ & $75.5 \%$ & 0.038 & $1.22(1.01-1.46)$ \\
\hline$\geq 51 \mathrm{~min}$ & $81.5 \%$ & $<0.001$ & $1.74(1.42-2.12)$ \\
\hline
\end{tabular}

Categorical values are shown as proportions (\%). Reference category: no change or exacerbation in symptoms.

$\mathrm{CI}$, confidence interval; Imp. R, improvement rate of symptoms in each factor; MQL-10, 10-item MOA quality-of-life questionnaire; OPT, Okada Purifying Therapy. toms, the improvement rates did not differ between the two groups, except for physical pain in those from Thailand $(70.2 \% / 84.4 \%, p<0.05)$ and dizziness/palpitation in the subjects from the United States $(66.4 \% / 82.3 \%, p<0.05)$ (Table 9$)$.

\section{Discussion}

This study adopted the convenience sampling method, which inevitably led to the recruitment of subject groups biased in favor of people sympathetic to or skilled in OPT. Moreover, a large proportion of treatments occurred in an authorized location where OPT was promoted. In addition, there were large discrepancies in the participants' characteristics between countries. While these shortcomings remain, nonetheless, this study is presumably the first international survey conducted to examine ethnic/cultural differences in the outcomes of biofield therapy.

Past studies have reported on numerous factors associated with the use of biofield therapy, such as the recipient's ethnicity, gender, socioeconomic status, and/or health condition. $^{10,11,31-34,39,40}$ In terms of factors associated with improved outcomes, the research team previously reported that female gender, positive reasons for receiving the therapy, an authorized location, and a longer therapy were independently associated with improvement of various symptoms after a single OPT session in individuals from Japan. $^{24}$ This is in line with study by Kristoffersen et al., which indicated a higher frequency of self-reports from female than male clients on improvement of various symptoms after receiving energy healing. ${ }^{10}$

The present study revealed that participants from Chile/Peru self-reported the improvement in overall symptoms, physical pain, anxiety/depression, and dizziness/palpitation more often than those from Japan, the United States, and Thailand. Participants from Japan, on the contrary, consistently indicated the lowest improvement rate for each of the different symptoms. Even after adjusting for other demographic factors, participant's country of residence still remained the most significant factor associated with the changes in symptoms. 


\begin{tabular}{|c|c|c|c|c|}
\hline \multirow{3}{*}{$\begin{array}{c}\text { Japan }(\mathrm{n}=2305) \\
\text { United States }(\mathrm{n}=294)\end{array}$} & improved & \multicolumn{2}{|c|}{ no change } & rbated \\
\hline & \multicolumn{2}{|l|}{$71.2 \%$} & & $1.6 \%$ \\
\hline & \multicolumn{2}{|l|}{$72.1 \%$} & $26.2 \%$ & $1.7 \%$ \\
\hline Thailand $(n=437)$ & \multicolumn{2}{|l|}{$76.0 \%$} & $21.7 \%$ & $2.3 \%$ \\
\hline Chile/Peru $(\mathrm{n}=312)$ & \multicolumn{2}{|l|}{$91.7 \%$} & $6.7 \%$ & $1.6 \%$ \\
\hline Portugal $(\mathrm{n}=80)$ & \multicolumn{2}{|l|}{$77.5 \%$} & $22.5 \%$ & $0.0 \%$ \\
\hline Spain $(n=38)$ & \multicolumn{2}{|l|}{$79.0 \%$} & $18.4 \%$ & $2.6 \%$ \\
\hline Argentina $(n=28)$ & \multicolumn{2}{|l|}{$75.0 \%$} & $17.9 \%$ & $7.1 \%$ \\
\hline $\operatorname{Mexico}(n=10)$ & \multicolumn{2}{|l|}{$100 \%$} & $0.0 \%$ & $0.0 \%$ \\
\hline Brazil $(n=10)$ & \multicolumn{2}{|l|}{$100 \%$} & $0.0 \%$ & $0.0 \%$ \\
\hline South Korea $(\mathrm{n}=24)$ & $37.5 \%$ & \multicolumn{2}{|l|}{$58.3 \%$} & $4.2 \%$ \\
\hline Taiwan $(\mathrm{n}=6)$ & $50.0 \%$ & \multicolumn{2}{|c|}{$50.0 \%$} & $0.0 \%$ \\
\hline Belgium/France $(n=8)$ & $62.5 \%$ & \multicolumn{2}{|c|}{$37.5 \%$} & $0.0 \%$ \\
\hline
\end{tabular}

FIG. 5. Self-reported changes in dizziness/palpitation after a single session of Okada Purifying Therapy. ${ }^{*} p<0.0083$ by the Mann-Whitney test between the participants from Japan, the United States, Thailand, and Chile/Peru.
Table 7. Logistic Regression Analysis of THE FaCtors AsSOCIATED With an IMPROVEMENT of DizZINESS/Palpitation $(N=2704)$

\begin{tabular}{|c|c|c|c|}
\hline & Imp. $R$ & $\mathrm{p}$-Value & $\begin{array}{c}\text { Odds ratio } \\
(95 \% \mathrm{CI})\end{array}$ \\
\hline \multicolumn{4}{|l|}{ Country of residence } \\
\hline Japan & $71.8 \%$ & & 1 \\
\hline The United States & $71.4 \%$ & 0.42 & \\
\hline Thailand & $77.0 \%$ & 0.001 & $1.79(1.29-2.51)$ \\
\hline Chile/Peru & $90.6 \%$ & $<0.001$ & $4.29(2.44-7.57)$ \\
\hline Age & & 0.98 & \\
\hline Gender & & 0.26 & \\
\hline Presence of illness & & 0.87 & \\
\hline $\begin{array}{l}\text { Reasons for } \\
\text { participation }\end{array}$ & & 0.32 & \\
\hline MQL-10 score & & 0.66 & \\
\hline OPT practitioner & & 0.43 & \\
\hline $\begin{array}{l}\text { Previous OPT } \\
\text { experience }\end{array}$ & & 0.11 & \\
\hline \multicolumn{4}{|l|}{$\begin{array}{l}\text { Location of OPT } \\
\text { administration }\end{array}$} \\
\hline Participant's home & $67.7 \%$ & & 1 \\
\hline $\begin{array}{l}\text { MOA's institute/ } \\
\text { workshop }\end{array}$ & $75.3 \%$ & 0.34 & \\
\hline Investigator's house & $78.3 \%$ & $<0.001$ & $1.68(1.32-2.15)$ \\
\hline \multicolumn{4}{|c|}{ Duration of OPT administration } \\
\hline $30 \mathrm{~min}$ & $72.4 \%$ & & 1 \\
\hline $31-50 \mathrm{~min}$ & $71.3 \%$ & 0.55 & \\
\hline$\geq 51 \mathrm{~min}$ & $77.2 \%$ & 0.002 & $1.44(1.14-1.82)$ \\
\hline
\end{tabular}

Categorical values are shown as proportions (\%). Reference category: no change or exacerbation in symptoms.

$\mathrm{CI}$, confidence interval; Imp. R, improvement rate of symptoms in each factor; MQL-10, 10-item MOA quality-of-life questionnaire; OPT, Okada Purifying Therapy.
Interestingly, those from Spanish/Portuguese speaking countries almost always showed higher improvement rates in various symptoms compared to other countries. Haack et al. mentioned that Latin America is a culturally rich region of the world with diverse perspectives on health. ${ }^{41}$ People living in those countries are often more holistic and spiritual and pay greater attention to psychologic, social, emotional, and spiritual aspects of disorder based on their cultural beliefs. ${ }^{38,41,42}$ In contrast, population in Japan usually rely on Western medicine, which is easy to access and paid by the national insurance. Laying-on-ofhands is neither a major Japanese traditional healing practice nor a common religious ritual, and thus many of these subjects may have been skeptical toward the effectiveness of OPT from the beginning.

On the contrary, Thailand is a notable Buddhist country, and the United States is a multiethnic country that comprises immigrants who are linked to the culture of origin with discrepancy in the degree of acculturation. For instance, African Americans reportedly have more spiritual mindset than other ethnic groups. ${ }^{43}$ Furthermore, Bair et al. described that white and Chinese American women often used spiritual therapies when they suffered psychologic symptoms, whereas Japanese American women did not. ${ }^{44}$

Participants who held strong ethnic identities and/or those who had spiritual mindset might call their own indigenous practices to mind during the OPT session. Alternatively, Japanese descendants may have had a positive or negative interpretation of OPT, which was often introduced in the Japanese community. Various proportions of such individuals in the population may have been represented in the study, which resulted in differences of changes in symptoms between countries.

Perception of symptoms may also differ based on ethnicity. Hispanic and/or people of African descent were reportedly more likely to suffer from physical pain, ${ }^{45,46}$ higher pain intensity, ${ }^{46}$ and antenatal depression ${ }^{47,48}$ than non-Hispanic white. Aufiero et al. described from their 
Table 8. Logistic Regression Analyses of the Factors Associated WITH AN IMPROVEMENT OF SyMPTOMS IN PARTICIPANTS FROM JAPAN

\begin{tabular}{|c|c|c|c|}
\hline & $\begin{array}{c}\text { Physical pain } \\
\text { Odds ratio }(95 \% \text { CI) }\end{array}$ & $\begin{array}{l}\text { Anxiety/depression } \\
\text { Odds ratio (95\% CI) }\end{array}$ & $\begin{array}{l}\text { Dizziness/palpitation } \\
\text { Odds ratio }(95 \% \text { CI }\end{array}$ \\
\hline \multicolumn{4}{|l|}{ Age } \\
\hline \multicolumn{4}{|l|}{ Gender } \\
\hline Male & & 1 & \\
\hline Female & & $1.24(1.01-1.51)$ & \\
\hline \multicolumn{4}{|l|}{ Presence of illness } \\
\hline \multicolumn{4}{|l|}{ Reasons for participation } \\
\hline \multicolumn{4}{|l|}{ MQL-10 score } \\
\hline \multicolumn{4}{|l|}{ OPT practitioner } \\
\hline \multicolumn{4}{|l|}{ Previous OPT experience } \\
\hline Never/seldom & 1 & & \\
\hline Sometimes/regularly & $1.29(1.06-1.59)$ & & \\
\hline \multicolumn{4}{|l|}{ Location of OPT administration } \\
\hline Participant's home & & 1 & 1 \\
\hline MOA's institute/workshop & & & \\
\hline Investigator's house & & $1.35(1.10-1.65)$ & $1.67(1.31-2.14)$ \\
\hline \multicolumn{4}{|l|}{ Duration of OPT administration } \\
\hline $30 \mathrm{~min}$ & 1 & 1 & 1 \\
\hline $31-50 \mathrm{~min}$ & $1.19(1.01-1.41)$ & $1.30(1.06-1.59)$ & \\
\hline$\geq 51 \mathrm{~min}$ & $1.49(1.25-1.78)$ & $1.70(1.37-2.11)$ & $1.48(1.15-1.90)$ \\
\hline
\end{tabular}

Categorical values are shown as proportions (\%). Reference category: no change or exacerbation in symptoms.

MQL-10, 10-item MOA quality-of-life questionnaire; OPT, Okada Purifying Therapy.

experimental study that Latino Americans and women reported greater pain with a standardized pain stimulus compared to Caucasian Americans and men. ${ }^{49}$ Those suffering from marked symptoms may have been relieved to some extent more often than those with mild symptoms.

In addition, ethnicity and/or culture may moderate placebo response. Walach and Jonas defined placebo response as the effect that is due to the meaning of a therapeutic intervention for a particular patient and context. ${ }^{35}$ They additionally described that the meaning arises from the interaction between the external environment and the internal conditions of persons, their history, social circumstances, individual predilections, and their expectations. In the present study, several factors, including location and duration of the OPT administration, and reasons for participation were likely to be associated with placebo response. Race and ethnicity may also influence the quality of provider-client interactions. ${ }^{36,37}$ The mere fact of being observed may have induced improvement in symptoms for some participants (positive Hawthorne effect) ${ }^{50-52}$ on the contrary, some may have overexpressed symptoms, for instance, as a means to express the desire to be taken seriously (negative Hawthorne effect). ${ }^{52}$ Leurent et al. described the presence of Hawthorne effect in health professionals, who changed their practices when they were being observed. ${ }^{53}$ Investigators' expectations (Pygmalion effect) may also have affected participants' judgment on the effectiveness of OPT. ${ }^{54,55}$ These factors may have increased the outcome differences among participants with ethnic/cultural differences.

Comparison between the present study and the team's previous study ${ }^{24}$ revealed that the improvement rates of physical pain, anxiety/depression, and dizziness/palpitation in the present study were consistently higher than in the previous study; $74.2 \%$ versus $69.7 \%, 75.2 \%$ versus $71.2 \%$, and $71.2 \%$ versus $67.5 \%$, respectively. A longer

Table 9. Improvement Rates of Symptoms After Receiving Okada Purifying Therapy AT AN MOA AFFILIATED INSTITUTE OR WORKSHOP

\begin{tabular}{lcccrr}
\hline & OPT practitioner & Overall symptoms & Physical pain & Anxiety/depression & Dizziness/palpitation \\
\hline Japan & No & $157 / 237(66.2 \%)$ & $130 / 170(76.5 \%)$ & $91 / 119(76.5 \%)$ & $52 / 81(64.2 \%)$ \\
& Yes & $919 / 1101(83.5 \%)^{*}$ & $715 / 967(73.9 \%)$ & $473 / 616(76.8 \%)$ & $330 / 462(71.4 \%)$ \\
United States & No & $412 / 544(75.7 \%)$ & $262 / 364(72.0 \%)$ & $216 / 286(75.5 \%)$ & $91 / 137(66.4 \%)$ \\
& Yes & $320 / 352(90.9 \%)^{*}$ & $216 / 284(76.1 \%)$ & $101 / 133(75.9 \%)$ & $65 / 79(82.3 \%)$ \\
Thailand & No & $638 / 831(76.8 \%)$ & $455 / 648(70.2 \%)$ & $341 / 423(80.6 \%)$ & $250 / 323(77.4 \%)$ \\
& Yes & $106 / 110(96.4 \%)^{*}$ & $81 / 96(84.4 \%)^{*}$ & $55 / 63(87.3 \%)$ & $33 / 44(75.0 \%)$ \\
Chile/Peru & No & $524 / 557(94.1 \%)$ & $285 / 317(89.9 \%)$ & $332 / 357(93.0 \%)$ & $168 / 184(91.3 \%)$ \\
& Yes & $80 / 81(98.8 \%)$ & $51 / 56(91.1 \%)$ & $49 / 56(87.5 \%)$ & $33 / 34(97.1 \%)$ \\
\hline
\end{tabular}

$\mathrm{a} / \mathrm{b}(\mathrm{c} \%)^{*}$ indicates the $p$-value between the comparison of the improvement rate in "No" OPT practitioners (those with never/seldom

OPT experience) and the rate in "Yes" OPT practitioners (qualified OPT practitioners) is less than 0.05 by Mann-Whitney test.

OPT, Okada Purifying Therapy. 
OPT administration was consistently associated with symptom improvement in both studies. The investigators who provided the therapy may have continued the treatment until the participants felt better. Alternatively, the participants may have reported positive changes due to psychologic satisfaction from longer treatments. ${ }^{24}$ Location of the administration and participants' gender remained the factors related to the improvement of different symptoms.

In the present study, qualified OPT practitioners did not always report their symptom changes more positively than did those with never/seldom OPT experience, regardless of their country of residence. Reece et al. reported that nonpractitioners of Johrei healing experienced a greater effect after the session than practitioners. ${ }^{16}$ Sufficient information may provide both advantages and disadvantages to the effectiveness of various therapies. Individuals with qualification as a practitioner and/or sufficient previous experience may have compared the particular experience of therapy received during the study with their past impressive experience, drawing a critical evaluation.

The exacerbation rates of symptoms after a single OPT administration varied in the range of $0.7 \%$ and $2.5 \%$ in the team's previous study. ${ }^{24}$ The present study revealed that $0.8 \%$ to $2.8 \%$ of the participants experienced symptom exacerbation. None of them needed emergency medical treatment, in which case OPT may be a useful complementary method for individuals in various situations, including for those seeking whole-person health, those wishing to recover from various symptoms, and for those receiving end-of-life care.

There were several limitations in the study design. First, the survey was not experimental as it used a convenience sample without an appropriate control or comparison group. As mentioned earlier, this study included a high percentage of elderly and/or female participants, and those having a qualification of OPT practitioner. In addition, OPT was frequently administered in an authorized location. All of these factors may have created a bias. The present study reveals neither the effectiveness of OPT in the general population nor of effectiveness of general biofield therapy.

Second, it may have been difficult for recipients to reveal their honest evaluations in the situation that their responses were presented to practitioners with whom they worked. Practitioners may have had recipients self-report a better outcome intentionally or unintentionally.

Third, some data may have not been recorded correctly during the data collection and/or during data entry for analyses. The possibility of potential cheating, such as changing of scores on the records by the practitioners, also cannot be denied.

Fourth, the information sheet and the questionnaires may not have been properly translated into each respective language. Moreover, some symptoms such as anxiety, dizziness, and palpitation may have different meanings in different languages, which influence the outcomes among those with ethnic/cultural differences.

Fifth, the factors that were assessed in the questionnaire were not exhaustive, and other factors may have contributed to the outcomes. Additional studies with rigorous study protocols are warranted to further investigate the effectiveness of OPT.

\section{Conclusions}

In those who were often sympathetic to OPT and/or in an authorized location, a single session of the therapy lasting 30 min or longer administered from volunteer practitioners was effective and safe across countries with ethnic/cultural differences. The improvement rates were consistently higher, among participants from Chile/Peru than those from Japan, the United States, and Thailand, and among those who had received a longer therapy. Spanish/Portuguese speaking countries almost always showed high improvement rates, conversely, Japan showed a lower rate in each symptom. Participants' gender, reasons for participation, previous experience, and location of receiving the session were also associated with the improvement of different symptoms.

Most of the participants who expressed exacerbation of symptoms recovered in a few hours. None of them needed emergency medical treatment.

\section{Acknowledgments}

The authors deeply appreciate the contributions from the MOA International Corporation, instructors and certified practitioners of Okada Purifying Therapy, and staff of MOA Health Science Foundation, whose participation made this study possible.

\section{Author Disclosure Statement}

The research team declares no conflict of interest in preparing and publishing this article. No competing financial interests exist.

\section{Funding Information}

The MOA Health Science Foundation financially supported the development of the questionnaires and data analyses of this study. The MOA International Corporation translated related documents into different languages, supported the Okada Purifying Therapy instructors, provided the facilities, reimbursed expenses for the lectures to the investigators, and also permitted the research team to use the affiliated institutes for the administration of the intervention. Neither the MOA Health Science Foundation nor the MOA International Corporation had any direct role in the study design, data collection and analyses, interpretation of the data, or writing the report. Neither the authors nor MOA Health Science Foundation received any financial support from the MOA International Corporation.

\section{References}

1. Jain S, Hammerschlag R, Mills P, et al. Clinical studies of biofield therapies: Summary, methodological challenges, and recommendations. Glob Adv Health Med 2015; 4(Suppl):58-66.

2. Guarneri E, King RP. Challenges and opportunities faced by biofield practitioners in global health and medicine: A white paper. Glob Adv Health Med 2015;4(Suppl):89-96.

3. Carneiro EM, Barbosa LP, Marson JM, et al. Effectiveness of Spiritist "passe" (Spiritual healing) for anxiety levels, depression, pain, muscle tension, well-being, and physiological parameters in cardiovascular inpatients: A randomized controlled trial. Complement Ther Med 2017;30: 73-78. 
4. Baldwin AL, Rand WL, Schwartz GE. Practicing Reiki does not appear to routinely produce high-intensity electromagnetic fields from the heart or hands of Reiki practitioners. J Altern Complement Med 2013;19:518-526.

5. Baldwin AL, Trent NL. An integrative review of scientific evidence for reconnective healing. J Altern Complement Med 2017;23:590-598.

6. Aghabati N, Mohammadi E, Esmaiel ZP. The effect of therapeutic touch on pain and fatigue of cancer patients undergoing chemotherapy. Evid Based Complement Alternat Med 2010;7:375-381.

7. Sagkal Midilli T, Ciray Gunduzoglu N. Effects of Reiki on pain and vital signs when applied to the incision area of the body after cesarean section surgery: A single-blinded, randomized, double-controlled study. Holist Nurs Pract 2016;30:368-378.

8. Baldwin AL, Vitale A, Brownell E, et al. Effects of Reiki on pain, anxiety, and blood pressure in patients undergoing knee replacement: A Pilot Study. Holist Nurs Pract 2017; 31:80-89.

9. Jahantiqh F, Abdollahimohammad A, Firouzkouhi M, Ebrahiminejad V. Effects of Reiki versus physiotherapy on relieving lower back pain and improving activities daily living of patients with intervertebral disc hernia. J Evid Based Integr Med 2018;23:1-5

10. Kristoffersen AE, Stub T, Knudsen-Baas O, et al. Selfreported effects of energy healing: A prospective observational study with pre-post design. Explore 2019;15:115-125.

11. Rahtz E, Child S, Knight S, et al. Clients of UK healers: A mixed methods survey of their demography, health problems, and experiences of healing. Complement Ther Clin Pract 2019;35:72-77.

12. Billot M, Daycard M, Wood C, Tchalla A. Reiki therapy for pain, anxiety and quality of life. BMJ Support Palliat Care 2019;9:434-438.

13. Rosada RM, Rubik B, Mainguy B, et al. Reiki reduces burnout among community mental health clinicians. J Altern Complement Med 2015;21:489-495.

14. Carneiro EM, Moraes GV, Terra GA. Effectiveness of Spiritist Passe (Spiritual Healing) on the psychophysiological parameters in hospitalized patients. Adv Mind Body Med 2016;30:4-10.

15. Friedman RSC, Burg MM, Miles P, et al. Effects of Reiki on autonomic activity early after acute coronary syndrome. J Am Coll Cardiol 2010;56:995-996.

16. Reece K, Schwartz GE, Brooks AJ, Nangle G. Positive well-being changes associated with giving and receiving Johrei healing. J Altern Complement Med 2005;11:455457.

17. MOA International. Purifying therapy program. Online document at: moainternational.or.jp/english/, accessed March 1, 2020.

18. MOA International. Chapter one: Practical side of administration. In: Explanation and Practice of Okada Purifying Therapy. Shizuoka, Japan: MOA International Press, 2004: 57-104.

19. Uchida S, Ueno M, Sugano H, Nitta K. Effect of external Qi, a Chinese alternative medicine, on an electroencephalogram and the autonomic nervous system-Difference between suggestion effect and external Qi effect. J Intl Soc Life Info Sci 2002;20:453-454.

20. Uchida S, Iha T, Yamaoka K, et al. Effect of biofield therapy in the human brain. J Altern Complement Med 2012;18:875-879.
21. Uchida S, Ueno M, Sugano H, Nitta K. Effect of external Qi on the autonomic nervous system-Difference of effect in expertise of healers. J Intl Soc Life Info Sci 2003;21:115-117.

22. Uchida S, Yamaoka K, Sugano H, Hatayama M. Effect of external Qi (MOA purifying therapy) on heart rate variability in climacteric women. J Intl Soc Life Info Sci 2004; 22:561-562.

23. Suzuki K, Uchida S, Kimura T, Katamura H. Safety and efficacy of biofield therapy in Japan. J Soc Integr Med Jpn 2009;2:37-43 (English Abstr).

24. Suzuki K, Uchida S, Kimura T, Katamura H. A large crosssectional, descriptive study of self-reports after biofield therapy in Japan: Demography, symptomology, and circumstances of treatment administration. Altern Ther Health Med 2012;18:38-50.

25. Hatayama M, Suzuki K, Ishida A, et al. Long-term efficacy of Okada Purifying Therapy (Bio-Energy Healing) on menopausal symptoms. Res Rep MOA Health Sci Found 2009;12:5-12.

26. Mikobi Minga T, Kure Koto FK, Egboki H, Suzuki K. Effectiveness of biofield therapy for individuals with sickle cell disease in Africa. Altern Ther Health Med 2014;20: 20-26.

27. Sarmento F, Tanaka H, Cordeiro E, Suzuki K. Effectiveness of biofield therapy for patients diagnosed with fibromyalgia. Altern Ther Health Med 2017;23:e7.

28. Suzuki K, Katamura H. Effectiveness of integrative healthcare support on hypertensive patients. J Soc Integr Med Jpn 2017;10:186-195 (English Abstr).

29. Suzuki K, Kimura T, Uchida S, et al. The influence of a multimodal health program with diet, art, and biofield therapy on the quality of life of people in Japan. J Altern Complement Med 2019;25:336-345.

30. Kimura T, Suzuki K, Uchida S, Katamura H. Responsiveness and minimally important difference of a generic quality of life measure for complementary health practices. Altern Med Stud 2012;2;e12.

31. Arcury TA, Suerken CK, MS, Grzywacz JG, et al. Complementary and alternative medicine use among older adults: Ethnic variation. Ethn Dis 2006;16:723-731.

32. Rhee TG, Evans RL, McAlpine DD, Johnson PJ. Racial/ethnic differences in the use of complementary and alternative medicine in US adults with moderate mental distress: Results from the 2012 national health interview survey. J Prim Care Community Health 2017;8:43-54.

33. Gillum F, Griffith DM. Prayer and spiritual practices for health reasons among American adults: The role of race and ethnicity. J Relig Health 2010;49:283-295.

34. Levin J, Taylor RJ, Chatters LM. Prevalence and sociodemographic correlates of spiritual healer use: Findings from the national survey of American life. Complement Ther Med 2011;19:63-70.

35. Walach H, Jonas WB. Placebo research: The evidence base for harnessing self-healing capacities. J Altern Complement Med 2004;10:S103-S112.

36. Bhugra D, Ventriglio A. Do cultures influence placebo response? Acta Psychiatr Scand 2015;132:227-230.

37. Friesen P, Blease C. Placebo effects and racial and ethnic health disparities: An unjust and underexplored connection. J Med Ethics 2018;44:774-781.

38. Bedi RP. Racial, ethnic, cultural, and national disparities in counseling and psychotherapy outcome are inevitable but eliminating global mental health disparities with indigenous healing is not. Arch Sci Psychol 2018;6:96-104. 
39. Rhodes PJ, Small N, Ismail H, Wright JP. The use of biomedicine, complementary and alternative medicine, and ethnomedicine for the treatment of epilepsy among people of South Asian origin in the UK. BMC Complement Altern Med 2008;8:7.

40. Ghiasuddin A, Wong J, Siu AM. Ethnicity, traditional healing practices, and attitudes towards complementary medicine of a pediatric oncology population receiving healing touch in Hawaii. Asia Pac J Oncol Nurs 2015;2: 227-231.

41. Haack SL, Mazar I, Carter EM, et al. Cultural sensitivity and global pharmacy engagement in Latin America: Argentina, Brazil, Ecuador, Guatemala, and Mexico. Am J Pharm Educ 2019;83:682-698.

42. Gureje O, Nortje G, Makanjuola V, et al. The role of global traditional and complementary systems of medicine in the treatment of mental health disorders. Lancet Psychiatry 2015;2:168-177.

43. Conner AL, Boles DZ, Markus HR, et al. Americans' health mindsets: Content, cultural patterning, and associations with physical and mental health. Ann Behav Med 2019;53:321-332.

44. Bair YA, Gold EB, Greendale GA, et al. Ethnic differences in use of complementary and alternative medicine at midlife: Longitudinal results from SWAN participants. Am J Public Health 2002;92:1832-1840.

45. Dobscha SK, Soleck GD, Dickinson KC, et al. Associations between race and ethnicity and treatment for chronic pain in the VA. J Pain 2009;10:1078-1087.

46. Lavin R, Park J. A characterization of pain in racially and ethnically diverse older adults: A review of the literature. J Appl Gerontol 2014;33:258-290.

47. Walmer R, Huynh J, Wenger J, et al. Mental health disorders subsequent to gestational diabetes mellitus differ by race/ethnicity. Depress Anxiety 2015;32:774-782.

48. Mukherjee S, Trepka MJ, Pierre-Victor D, et al. Racial/ ethnic disparities in antenatal depression in the United States: A systematic review. Matern Child Health J 2016; 20:1780-1797.
49. Aufiero M, Stankewicz H, Quazi S, et al. Pain perception in Latino vs. Caucasian and male vs. female patients: Is there really a difference? West J Emerg Med 2017;18:737742.

50. McCambridge J, Witton J, Elbourne DR. Systematic review of the Hawthorne effect: New concepts are needed to study research participation effects. J Clin Epidemiol 2014;67: 267-277.

51. Vetter TR, Mascha EJ. Bias, Confounding, and interaction: Lions and tigers, and bears, oh my! Anesth Analg 2017; 125:1042-1048.

52. Berthelot JM, Nizard J, Maugars Y. The negative Hawthorne effect: Explaining pain overexpression. Joint Bone Spine 2019;86:445-449.

53. Leurent B, Reyburn H, Muro F, et al. Monitoring patient care through health facility exit interviews: An assessment of the Hawthorne effect in a trial of adherence to malaria treatment guidelines in Tanzania. BMC Infect Dis 2016;16: 59.

54. Natanovich G, Eden D. Pygmalion effects among outreach supervisors and tutors: Extending sex generalizability. J Appl Psychol 2008;93:1382-1389.

55. Szumski G, Karwowski M. Exploring the Pygmalion effect: The role of teacher expectations, academic self-concept, and class context in students' math achievement. Contemp Educ Psychol 2019;59:101787.

Address correspondence to: Kiyoshi Suzuki, MD, PhD General Incorporated Foundation MOA Health Science Foundation 4-8-10 Takanawa Minato-ku Tokyo 108-0074 Japan

E-mail: k.suzuki@mhs.or.jp 